\title{
FLOOD WATER LEVEL FORECASTING WITH STABLE ACCURACY USING NONLINEAR AUTOREGRESSIVE EXOGENOUS NEURAL NETWORK
}

\author{
Amrul Faruq. ${ }^{a, b}$, Shamsul Faisal Mohd Hussein. a, Che Munira Che Razali. ${ }^{a}$, \\ Shiref Abo Elnour. a, Shahrum Shah Abdullah. a,* \\ a Electronic Systems Engineering Department, Malaysia-Japan International Institute of Technology, \\ Universiti Teknologi Malaysia, MALAYSIA. \\ b Electrical Engineering Department, University of Muhammadiyah Malang, INDONESIA. \\ *Corresponding author: shahrum@utm.my
}

\begin{abstract}
This paper presents an improved lead time flood forecasting using Nonlinear Autoregressive Exogenous Neural Networks (NARXNN) technique. First, the model is trained by open-loop NARX model using four upper-rivers as exogenous input and one output flood water level of Kelantan River at Kuala Krai, Kelantan, Malaysia. Then a closed-loop sometimes called parallel model of NARX employed with reliable taped-delay times and number of hidden neurons to forecast water level in flood forecasting point (FFP). The model has been tested for multi-step-ahead of time water level at flood location. The result verified the high precision level of error prediction of the presented flood forecasting model.
\end{abstract}

Keywords: Floods, Forecasting, NARX, Neural Networks, Water Level

\section{INTRODUCTION}

Flood water level forecasting has been presented recently by [1], the feed forward multilayer perceptron (MLP) with Cuckoo search (CS) algorithm model could perform better for 2-hour ahead of time. Recent studies in Malaysia about disaster risk including floods has been discussed by the researchers [2], [3], [4], [5] and [6]. Some different ANN technique has been discussed over there, and these are often addressed for forecasting update, include error prediction thus far is an open issue in forecasting performance. 7-hour lead of time is the maximum time adjusted in these study. Hence, the aim of this work is to provide a multistep lead time flood water level forecasting utilizing the upper-river water level station as input employed with NARX neural networks technique. Kelantan River at Kuala Krai, Kelantan, Malaysia is selected as Flood Forecasting Point (FFP) in this work.

\section{METHODOLOGY}

The real-time water level dataset obtained from the Department of Irrigation and Drainage (DID), Malaysia, includes four upper-rivers Kelantan basin and one considered FFP. The two sets of inputs and outputs is created. These array are ( $\mathrm{Nx} 4)$ and $(\mathrm{Nx} 1)$ respectively used for training the network. To represent $1 \mathrm{hr}, 7 \mathrm{hr}$ and $10 \mathrm{hr}$ lead of time, a new set of inputs ( $\mathrm{Nx} 4)$ and $(\mathrm{Nx} 1)$ validation output is provided in order to perform multi-step-ahead prediction. These inputs is used for doing the forecasting process, and validated how good the network was performing by plotting the forecasting with the real outputs of $\mathrm{T}$ ahead of time. The NARXNN architecture with 4 input series and 1 output series as illustrated in Figure 1 . The flood water level forecast using NARX algorithm as follows; i) first, read input data which is water level in four upstream rivers and one water river in flood location. ii) defining input and output, four input data and one predicted output data. iii) partitioning training and testing data. iv) train data using Levenberg-Marquardt backpropagation technique then saved the trained neural network model. And v) predict time-step ahead output as test data using trained data. 
$5^{\text {th }}$ Malaysia-Japan Joint International Conference (MJJIC 2018)

$3^{\text {rd }}$ International Conference on Advanced Technology \& Applied Sciences (ICaTAS 2018)

$4^{\text {th }}$ JASTIP Symposium on Disaster Prevention International Cooperation Research

\section{DISCUSSION AND CONCLUSION}

The performance of NARX model is evaluated using Root Mean Square Error (RMSE) to measure the differences between the estimated water river output, $\hat{y}[n+T]$ and actual reference river water level, $y$. The real-time water level during flood periods in November 2011 is chosen to evaluate and develop the flood forecast model. (2880x4) input series and (2880x1) output series was used for training purposes. The trained model then used to test the model performance using new set of $(2880 \times 4)$ validation input and (2880x1) validation output represent to 1-hr, 7-hr and 10-hr ahead of time. Evaluation and performance result respectively shown in Figure 1 and Table 1.

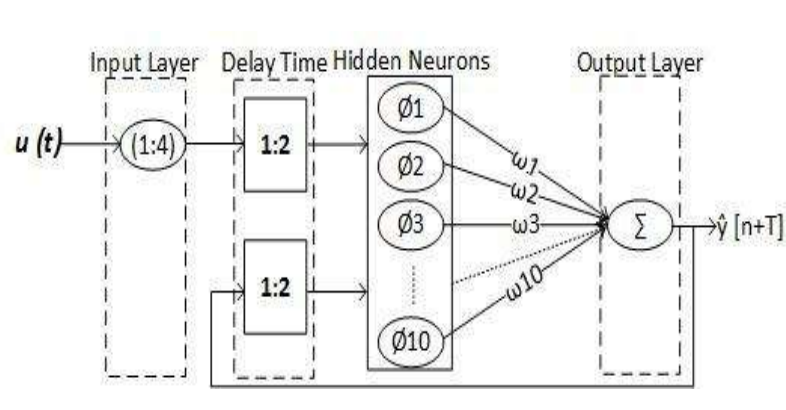

(a)

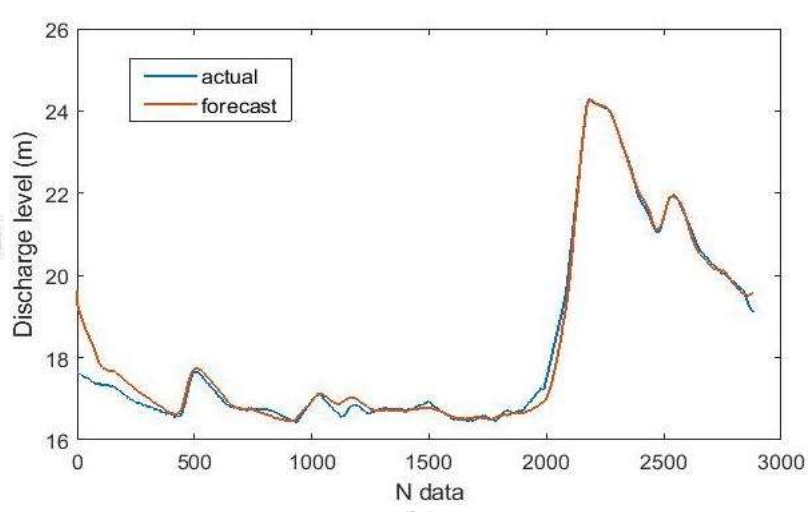

(b)

Figure 1. NARX Neural Network. a) parallel-model architecture, b) $10 \mathrm{hr}$ ahead evaluation result

Table 1. NARXNN performance result in several evaluations

\begin{tabular}{|l|l|l|l|l|l|l|l|l|l|}
\hline T ahead & \multicolumn{1}{|c|}{$1 \mathrm{hr}$} & \multicolumn{2}{|c|}{$7 \mathrm{hr}$} & \multicolumn{1}{l|}{$10 \mathrm{hr}$} \\
\hline RMSE & 0.186 & 0.210 & 0.194 & 0.215 & 0.272 & 0.299 & 0.273 & 0.269 & 0.306 \\
Bestfit (\%) & 91.851 & 90.825 & 91.519 & 90.627 & 88.145 & 86.925 & 88.085 & 88.270 & 86.651 \\
\hline
\end{tabular}

According to Table 1, it can be analyzed that the NARX network shows good performance in term of forecasting accuracy and error distribution. By the default of NARX network as 10 neurons and taped-delayline is 2 , these networks able to produce 0.186 RMSE with the best fit $91.85 \%$ for 1-hour lead of time flood forecasting. It can also be observed that the forecasting accuracy keeps on being stable for the adjusted time ahead until 10-hour lead of time. The best fit value of higher than $85 \%$ illustrated by the graph indicates that the flood forecasting performance is near-closed to the actual model.

\section{ACKNOWLEDGMENT}

The authors wish to express their sincerest gratitude to the Malaysia-Japan International Institute of Technology, Universiti Teknologi Malaysia for supporting and providing the facilities of this research.

\section{REFERENCES}

[1] S. Phitakwinai, S. Auephanwiriyakul, and N. Theera-Umpon, Proc. 2016. Int. Jt. Conf. Neural Networks, 2016(1): 519-524.

[2] N. W. Chan, Econ. 2012. Welf. Impacts Disasters East Asia Policy Responses., 2012: 503-551.

[3] M. S. Bin Khalid and S. B. Shafiai. 2015. Int. J. Soc. Sci. Humanit., 5(4): 398-402.

[4] F. A. Ruslan, A. M. Samad, M. Tajjudin, and R. Adnan, Proceeding - 2016 IEEE 12th Int. Colloq. Signal Process. its Appl. CSPA 2016, 2016: 263-268.

[5] S. Shafiai and M. S. Khalid. 2016. Int. Soft Sci. Conf., 1983: 1-8.

[6] M. Anuar, F. Azarshah, and A. Aziz. 2017. AsiaSim 2017: 225-234. 